Wright State University

CORE Scholar

\title{
Exploring Cost Constraints on Stem Elongation in Plants Using Phenotypic Manipulation
}

Don Cipollini

Wright State University - Main Campus, don.cipollini@wright.edu

Jack C. Schultz

Follow this and additional works at: https://corescholar.libraries.wright.edu/biology

Part of the Biology Commons, Plant Sciences Commons, and the Systems Biology Commons

\section{Repository Citation}

Cipollini, D., \& Schultz, J. C. (1999). Exploring Cost Constraints on Stem Elongation in Plants Using Phenotypic Manipulation. The American Naturalist, 153 (2), 236-242.

https://corescholar.libraries.wright.edu/biology/527

This Article is brought to you for free and open access by the Biological Sciences at CORE Scholar. It has been accepted for inclusion in Biological Sciences Faculty Publications by an authorized administrator of CORE Scholar. For more information, please contact library-corescholar@wright.edu. 


\section{Exploring Cost Constraints on Stem Elongation in Plants Using Phenotypic Manipulation}

Donald F. Cipollini ${ }^{\star}$ and Jack C. Schultz ${ }^{\dagger}$

Department of Entomology, Pennsylvania State University, University Park, Pennsylvania 16802

Submitted April 14, 1998; Accepted September 29, 1998

Keywords: adaptive phenotypic plasticity, gibberellic acid, opportunity costs, Phaseolus vulgaris.

Negative associations between individual life-history traits of an organism are referred to as life-history trade-offs (Stearns 1992; Zera et al. 1998). The existence of costly trade-offs is thought to have favored the evolution of phenotypic plasticity as a mechanism through which organisms can account for environmental heterogeneity while modulating costs and benefits incurred by fixed allocation to competing functions (Bradshaw 1965; Stearns 1992; Sultan 1995; Dudley and Schmitt 1996; Pigliucci 1996). In plants, the ability to modify stem elongation in response to environmental cues appears to be a classic form of adaptive phenotypic plasticity (Sultan 1995; Gedroc et al. 1996). Plastic increases or decreases in stem elongation rate in plants can be triggered by light-quality and lightquantity cues (Smith 1982; Ballaré et al. 1989, 1990; Rajapakse and Kelly 1995; Petit and Thompson 1997) and exposure to mechanical stimuli (e.g., wind) (Gartner 1991; Jaffe and Forbes 1993; Emery et al. 1994; Cipollini 1997b). Increased stem elongation in response to light cues can enable plants to escape shading by neighbors and capitalize on heterogenous resources, while reduced elongation in response to mechanical cues can enable plants to resist mechanical damage (Ballaré et al. 1991, 1995; Jaffe and Forbes 1993).

The best-studied plastic stem response in plants is the "shade avoidance" response, cued by altered red : far-red

\footnotetext{
* To whom correspondence should be addressed. Present address: Department of Ecology and Evolution, University of Chicago, Chicago, Illinois 60637; email: dcipolli@midway.uchicago.edu.

† E-mail: ujq@psu.edu.

Am. Nat. 1999. Vol. 153, pp. 236-242. (c) 1999 by The University of Chicago. 0003-0147/99/5302-0007\$03.00. All rights reserved.
}

(R:FR) light ratio and mediated by phytochrome (Smith 1982; Ballaré et al. 1991, 1995; Weiner and Thomas 1992; see Pigliucci 1996 for discussion). While the adaptive value of this response to plants in crowded situations has been widely hypothesized, its effect on maximizing fitness has rarely been measured. Using mutant Brassica rapa and transgenic tobacco plants with disabled phytochrome responses, Schmitt et al. (1995) demonstrated that elongated phenotypes had higher fitness when at high density, while nonelongated (suppressed) phenotypes had higher fitness at low density. By manipulating stem elongation in Impatiens capensis with R:FR light and selection analysis, Dudley and Schmitt (1996) demonstrated that selection favored elongated phenotypes at high density and suppressed phenotypes at low density. In this study, however, direct selection on height did not fully explain the lower fitness of elongated plants at low density, indicating that an intrinsic cost of stem elongation was present.

Although the existence of stem elongation costs has been suggested indirectly (Stearns 1992; Emery et al. 1994; Pigliucci 1997) and costly trade-offs involving allocation to competing organs are implicit in models of optimal foraging in plants (e.g., Gleeson and Tilman 1992), few studies have examined costs of stem elongation experimentally (e.g., Fitter and Ashmore 1974; Ballaré et al. 1991; Dudley and Schmitt 1996) or investigated their possible mechanistic basis (e.g., Ballaré et al. 1991; Methy and Roy 1993).

Opportunity costs are the costs of investing current resources in a particular structure or function (Bloom et al. 1985; Ballaré et al. 1991). If opportunity costs are not balanced through a gain in benefits (e.g., through increased resource capture), losses in growth or reproduction can result. Allocation models predict that plants should preferentially allocate resources to the organ(s) providing the highest fitness return or that provide access to the most limiting resource in their environment (Gleeson and Tilman 1992; Perrin 1992). Increased stem elongation may incur an opportunity cost if internal resources used in the production of stems are diverted away from resource-harvesting roots and leaves, leading to a cumulative decrease in resource capture and, ultimately, to decreased growth and reproduction (Bloom et al. 1985; Tilman 1988). For 
example, suboptimal allocation of resources to roots and leaves may explain the intrinsic costs of stem production in elongated plants detected by Dudley and Schmitt (1996). To reveal such mechanisms, experimental manipulations of stem elongation in the absence of the influence of selective forces are necessary to enhance the detection of costs.

Costs of investing resources in particular functions (e.g., defense vs. growth) should be even more noticeable in plants under resource limitation (Bazzaz et al. 1987). Thus, costs of stem elongation should be detected more readily in plants exposed to resource-limiting stresses, such as herbivory. Regrowth following leaf area loss in plants is often directed to the shoot at the expense of roots to replace lost leaf area (Bloom et al. 1985; Mihaliak and Lincoln 1989; Ovaska et al. 1993; Rosenthal and Kotanen 1994). Under these circumstances, costs of stem production may also include a reduced ability to compensate for leaf area removal, especially if increased stem production leads to reduced investment in roots and leaves.

Environmentally cued alterations in stem growth are mediated by plant hormones such as auxins, gibberellins, and ethylene (Biro and Jaffe 1984; Trewavas 1986; Jaffe and Forbes 1993). Gibberellic acid (GA) plays a well-documented role in stem elongation in plants (Lester et al. 1997). More important, alterations in endogenous GA content, metabolism, and/or tissue sensitivity mediate plastic stem elongation responses to changes in light quality (Sponsel 1986; Chory 1993; Toyomasu et al. 1994; Lopez-Juez et al. 1995). Exogenous application of GA can restore normal growth of mutant phenotypes and can produce stem morphologies that phenocopy those induced by environmental cues (Brown 1983; Biro and Jaffe 1984; Horrell et al. 1990; Toyomasu et al. 1994). For example, to examine patterns of morphological variation in the field, Brown (1983) and van Hinsberg (1997) have used GA to mimic the effects of shade on Plantago paradoxa and Plantago lanceolata, respectively. Manipulation of stem elongation with GA enables examination of the mechanistic basis of costs of stem elongation in plants of the same age in the absence of confounding factors, such as varying light (e.g., Dudley and Schmitt 1996) or ontogeny (Coleman et al. 1994; Gedroc et al. 1996; Pigliucci 1997). The elongated, phytochrome B-deficient $B$. rapa mutant used by Schmitt et al. (1995) contains 12 times the endogenous GA content of wild-type plants (Rood et al. 1990). Thus, although no exogenous application of GA was used, their study involved a phenotype altered by high endogenous levels of GA. Manipulation of phenotypic expression with hormones to mimic naturally occurring phenotypes has also been used to examine reproductive trade-offs in lizards (Sinervo and Huey 1990) and crickets (Zera et al. 1998), costs of defense in tobacco (Baldwin et al. 1990), and environmental controls on growth plasticity in Stellaria longipes (MacDonald et al. 1986; Emery et al. 1994).

To investigate the presence and mechanistic basis of costs of stem elongation, we exploited the ability of exogenously applied GA to induce stem elongation in common bean in a manner similar to that induced by lightquality cues, without the need to alter nutrient, moisture, and light regimes. We compared several growth and fitness attributes of GA-modified plants with untreated plants of the same age and developmental stage. We included a leaf area removal treatment to examine whether exposure to an additional resource stress would increase apparent costs of stem elongation. Our results indicate that stem elongation induced by GA was generally costly to growth and fitness and that the fundamental mechanism producing such costs is allocation of resources away from resourceharvesting roots and leaves to support increased stem growth. Leaf area removal tended to enhance the detectable costs of stem elongation.

\section{Material and Methods}

We utilized an inbred determinate bush cultivar of common bean Phaseolus vulgaris (cv. OSU 4091-G) that has very short internodes under high light conditions and exhibits plasticity in stem elongation in response to light quality and mechanical cues (Cipollini 1997b). Seeds were sown on July 1, 1994, in 1.5-L pots (two per pot) in a greenhouse under natural light in a mixture of vermiculite : perlite : sand $(3: 1: 1, \mathrm{v}: \mathrm{v}: \mathrm{v})$. Maximum midday light levels reached $\sim 1,400 \mu \mathrm{E} \mathrm{m}^{-2} \mathrm{~s}^{-1}$ PAR over the greenhouse benches. Plants were watered regularly throughout the experiment and fertilized once per week with $200 \mathrm{~mL}$ of Peter's 20-20-20 N-P-K soluble fertilizer (Grace-Sierra, Milpitas, Calif.). Plants were thinned to one seedling per pot when the primary leaves had just begun to expand, and the pots were spaced widely on the greenhouse benches. Plants were moved randomly within the greenhouse benches on a weekly basis.

We induced stem elongation by applying GA as a root drench (Morris and Arthur 1985). Sixteen plants received $100 \mathrm{~mL}$ of $10 \mu \mathrm{M} \mathrm{GA}_{3}$ solution (Sigma Chemical, St. Louis) once per week for $4 \mathrm{wk}$ after the initial placement of plants on benches. Crystalline $\mathrm{GA}_{3}$ was dissolved in $1 \mathrm{~mL}$ ethanol and made to volume with distilled water. We treated 16 plants designated as controls with the same solution but without $\mathrm{GA}_{3}$. This treatment was chosen based on its exact use in studies of the fundamental basis of stem elongation in bean (Morris and Arthur 1985) and its ability to mimic the phenotype produced by exposure of this bean cultivar to low R : FR in a growth chamber (D. Cipollini, personal observation). Internode, leaf, and branch number were unaffected by this treatment, as was date of first flowering. 
The primary direct effect of GA was to increase main stem and branch internode length and relative allocation of biomass to stem, mimicking the effects of lowered R:FR light on this cultivar. Bean plants treated with GA in this way exhibit decreased root and leaf mass production rate, decreased leaf area production rate, and increased stem mass production rate relative to untreated controls for the first 3-4 wk of growth; thus, altered allocation is established early by this treatment and is not simply an endof-season effect (Cipollini 1997b).

During weeks 4 and 5 (initial flowering stage), we damaged half of the plants in each treatment $(N=8)$ by removing $15 \%$ of the total leaf area of each plant with a sterilized paper hole punch. Half of this percentage was removed during week 4 and half during week 5 . The existence of a significant leaf area to leaf length relationship allowed us to estimate leaf area at the time of damage using leaf length. Damage was dispersed evenly over all leaves on each plant. Three weeks following leaf area removal, we measured final height and leaf area on all plants, separated them into stems (including petioles), leaves, roots, and pods, and dried them for $4 \mathrm{~d}$ at $60^{\circ} \mathrm{C}$. Leaf area was measured on fresh leaves using a Li-Cor Model 3100 Area Meter (Li-Cor, Lincoln, Nebr.). Mass measures were recorded from dried material. Allocation and ratio measures were calculated from dry masses.

Randomization of plants within treatments and among greenhouse benches allowed the use of a $2 \times 2$ full-factorial design. A set of correlated variables that we considered the best indicators of plant fitness (leaf area, total mass, pod number, and pod mass; Farris and Lechowicz 1990) were analyzed by MANOVA (Proc GLM, SAS Institute 1989) with $\mathrm{GA}_{3}$ treatment, leaf area removal (damage), and their interaction as effects. The $F$ and $P$ values from the multivariate tests were based on the Pillai's Trace test statistic. To examine more closely the possible mechanisms that produce costs, we analyzed all mass and allocation variables using separate ANOVAs (Proc GLM, SAS Institute 1989). Specific comparisons were made with Tukey's HSD test.

\section{Results}

Plants in which increased stem elongation had been induced by GA treatment exhibited reduced total biomass and reproduction at the end of the experiment. Leaf area, total mass, pod number, and total pod mass were greatly reduced by GA treatment (MANOVA: $F=4.337$, df $=$ $4,25, P=.0084)$ and less so by damage $(F=2.849$, $\mathrm{df}=4,25, P=.0449)$. Total seed mass was not measured in this study, but total pod mass and total seed mass are highly correlated in this cultivar, in both GA-treated and untreated plants (Cipollini 1997a). While the GA-treat- ment by damage interaction was not statistically significant ( $F=0.430, \mathrm{df}=4,25, P=.786)$, the effect of damage was consistently more severe in GA-treated plants than in controls; that is, costs of stem elongation tended to be more detectable in GA-treated plants when damaged relative to when they were undamaged (fig. 1). Univariate ANOVAs indicated that GA-treated plants were significantly taller than untreated controls $(F=56.27, \mathrm{df}=1,28, \quad P=$ $.0001)$ and allocated a greater percentage of their biomass to stem $(F=55.05, \mathrm{df}=1,28, P=.0001)$ and a lesser percentage to roots $(F=24.95, \mathrm{df}=1,28, P=.0001)$ than did controls. GA-treated plants also exhibited significantly reduced root mass $(F=19.82, \mathrm{df}=1,28, P=$ $.0001)$, leaf mass $(F=15.59, \mathrm{df}=1,28, P=.0005)$, leaf area $(F=17.31$, df $=1,28, P=.0003)$, root : shoot mass ratio $(F=21.91$, $\mathrm{df}=1,28, P=.0001)$, total mass $(F=$ 9.55, $\mathrm{df}=1,28, P=.0045)$, total pod mass $(F=6.60$, $\mathrm{df}=1,28, P=.0159)$, and pod number $(F=5.8, \mathrm{df}=$ $1,28, P=.001$; fig. 1 ).

\section{Discussion}

In this greenhouse experiment, where all plants were given the same amount of light, water, and nutrients, stem elongation induced by GA was generally costly to growth and reproduction. This indicates that investment in stem elongation incurred an opportunity cost that we could measure at the end of the season as reduced biomass and reproductive effort. Thus, while increased stem elongation may be advantageous to plants in competition for limiting light, intrinsic costs may explain the maladaptive nature of increased stem elongation when plants are grown in nonlimiting light conditions (Dudley and Schmitt 1996).

Our results indicate that the opportunity cost associated with allocation among resource-harvesting organs was the primary mechanism producing costs of stem elongation in this study (Bloom et al. 1985; Gleeson and Tilman 1992; Perrin 1992). Most studies have attributed the ability of GA to stimulate shoot production in plants to the creation of stronger photoassimilate sinks in the stem than in other organs and not to direct effects of GA on root or leaf assimilatory capacity or other pleiotropic effects (Mulligan and Patrick 1979; Morris and Arthur 1985; Yim et al. 1997). In this study, the primary phenotypic effect of GA was seen in stem and branch elongation. Alterations of leaf, branch, and internode number and flower development by GA, which could contribute to the costly nature of increased stem elongation in other plants (Smith and Whitelam 1990), were not seen in this experiment. Although unrecognized physiological effects of GA could be partly responsible for costs detected in this study, our results support the view that reduced growth and reproduction of GA-treated plants were largely due to reduced 

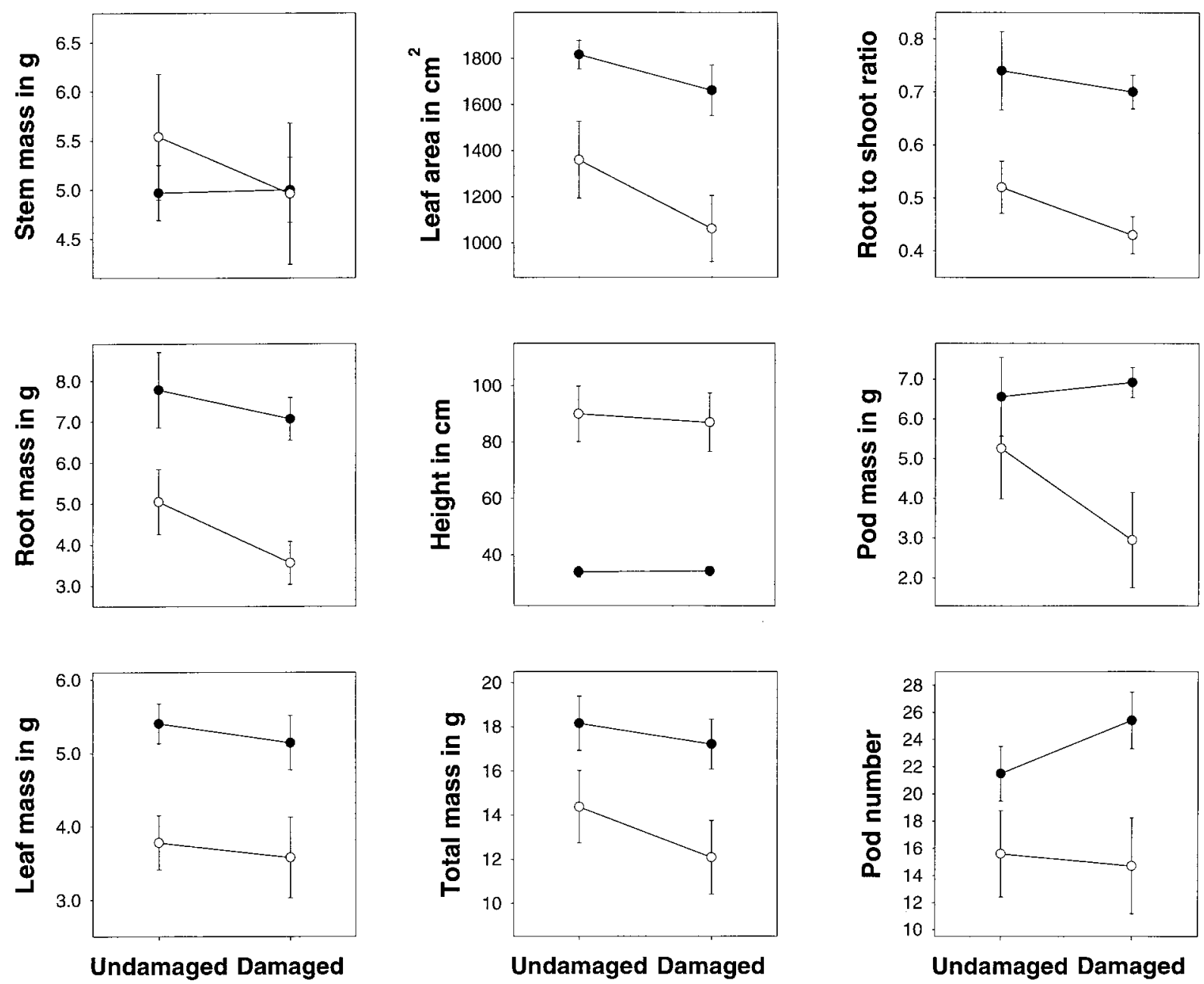

Figure 1: Growth and fitness attributes of control (filled circles) and elongated gibberellic acid-treated (open circles) bean plants across two damage treatments. Damage consisted of the removal of $15 \%$ of the total leaf area per plant. Each point represents the mean $( \pm$ SE) of eight replicate plants.

leaf and root growth and ultimately decreased resource capture. While GA treatment has no direct effect on photosynthesis of single leaves (e.g., Yim et al. 1997), bean plants treated with GA in this study exhibited decreased whole-shoot $\mathrm{CO}_{2}$ uptake rates on a per-gram shoot mass basis relative to controls on day 20 and day 28 after the initiation of the experiment (D. Cipollini, unpublished data). Increased allocation to stems at the expense of leaves in GA-treated plants evidently led to reduced whole-plant carbon gain, and reduced allocation to roots could have reduced nutrient uptake rates. We suggest that this allocation-based mechanism may also be partly responsible for the intrinsic costs of stem elongation detected in elongated Impatiens capensis plants by Dudley and Schmitt (1996), although other cost-producing mechanisms are undoubtedly important.
Reduced root : shoot ratio induced by GA-treatment also apparently contributed to a reduced ability to compensate for leaf area removal. The ability to tolerate leaf area removal in plants often is positively associated with a high root : shoot ratio, enabling resource translocation from roots to shoots following damage (e.g., van der Meijden et al. 1988; Lefevre et al. 1991; Lentz and Cipollini 1998; but see Obeso and Grubb 1994). In a companion study using the foliar application of GA to bean plants in the field, Cipollini (1997a) found that leaf area removal was more detrimental to fitness in elongated GA-treated plants than in untreated controls. Likewise, reduced root: shoot ratio induced by nitrate addition reduced the ability of Heterotheca subaxillaris to compensate for herbivory (Mihaliak and Lincoln 1989). We suggest that the tendency for GA to exacerbate the neg- 
ative effects of leaf area removal was due to the reduced root : shoot ratio induced by GA treatment in elongated plants in addition to the potential negative effects of GA on resource capture. This tendency could become more significant at higher levels of defoliation.

Our finding that costs of stem elongation are present and gain importance under additional resource-limiting stresses has broad ecological and evolutionary implications. The presence of costs may partly explain the evolution of plasticity in stem elongation, could constrain fixation of constitutively elongated phenotypes at the population level, and might restrict geographical distribution of constitutively elongated plants. Moreover, because stem elongation can exhibit costly trade-offs with other fitness enhancing traits, it may constrain the evolution of individual life-history traits (Stearns 1992). Other authors have suggested that costs of stem elongation include risks of physical breakage (Niklas 1992) and high rates of xylem embolism (Salisbury and Ross 1992; Wang et al. 1992). Costs of elongation could also arise through alterations in flower number and phenology, leaf and branch morphology, or other physiological effects (Smith and Whitelam 1990). We add reduced fitness via less effective resource acquisition and reduced tolerance to herbivory to this list. Regardless of the mechanism, balancing costs depends on improved access to resources-for example, by growth into resource-rich patches by overtopping neighbors. Balancing long-term costs of elongation might be more possible in a less seasonal environment, such as some tropical settings, perhaps contributing to the increased frequency of constitutive vines among tropical plants. In other environments, shifting costs and benefits have evidently favored stem elongation plasticity or fixation of suppressed (nonelongated) phenotypes.

In conclusion, the well-established role of GA in stem elongation (e.g., Lester et al. 1997) and its association with phytochrome-mediated stem responses (e.g., Sponsel 1986) enabled us to use GA to isolate costs of stem elongation in this study. In general, hormonal manipulation permits us to examine costs and trade-offs of phenotypes evoked by a particular environmental cue without the confounding effect of the environment. Hormonal manipulation has proven to be useful in other studies of phenotypic plasticity in stem elongation (e.g., Emery et al. 1994; van Hinsberg 1997) and is likely to be applicable to many other plant developmental traits.

\section{Acknowledgments}

We thank J. Bergelson, T. Juenger, K. Lentz, J. Lynch, M. Pigliucci, and A. Stephenson for their comments and/or contributions to this work. Comments by M. McPeek and two anonymous reviewers greatly improved an earlier ver- sion of this manuscript. This research was supported by National Science Foundation grant IBN-9630798 to J.C.S.

\section{Literature Cited}

Baldwin, I. T., C. L. Sims, and S. E. Kean. 1990. The reproductive consequences associated with inducible alkoloidal responses in wild tobacco. Ecology 71:252-262.

Ballaré, C. L., A. L. Scopel, and R. A. Sanchez. 1989. Photomodulation of axis extension in sparse canopies: role of the stem in the perception of light quality signals of stand density. Plant Physiology 89:1324-1330.

- 1990. Far-red radiation reflected from adjacent leaves: an early signal of competition in plant canopies. Science (Washington, D.C.) 247:329-332.

- 1991. On the opportunity cost of the photosynthate invested in stem elongation reactions mediated by phytochrome. Oecologia (Berlin) 86:561-567.

Ballaré, C. L., A. L. Scopel, M. L. Roush, and S. R. Radosevich. 1995. How plants find light in patchy canopies: a comparison between wild-type and phytochrome-b-deficient mutant plants of cucumber. Functional Ecology 9:859-868.

Bazzaz, F. A., N. R. Chiariello, P. D. Coley, and L. F. Pitelka. 1987. Allocating resources to reproduction and defense. BioScience 37:58-67.

Biro, K. L., and M. J. Jaffe. 1984. Thigmomorphogenesis: ethylene evolution and its role in the changes observed in mechanically perturbed bean plants. Physiologia Plantarum 62:289-296.

Bloom, A. J., F. S. Chapin, and H. A. Mooney. 1985. Resource limitation in plants-an economic analogy. Annual Review of Ecology and Systematics 16:363-392.

Bradshaw, A. D. 1965. Evolutionary significance of phenotypic plasticity in plants. Advances in Genetics 13: 115-155.

Brown, M. J. 1983. Phenotypic plasticity and stability of leaf form in Plantago paradoxa Hook f. in mosaic environments. Australian Journal of Botany 31:323-330.

Chory, J. 1993. Out of darkness: mutants reveal pathways controlling light-regulated development in plants. Trends in Genetics 9:167-172.

Cipollini, D. F. 1997a. Gibberellic acid treatment reduces the tolerance of field-grown common bean to leaf removal. Journal of Plant Growth Regulation 16:123-127. $1997 b$. The influence of induced alterations in morphology and physiology on plant tolerance and resistance to pests. Ph.D. diss. Pennsylvania State University, University Park.

Coleman, J. S., K. D. M. McConnaughay, and D. D. Ackerly. 1994. Interpreting phenotypic variation in plants. Trends in Ecology \& Evolution 9:187-191.

Dudley, S. A., and J. Schmitt. 1996. Testing the adaptive 
plasticity hypothesis: density-dependent selection on manipulated stem length in Impatiens capensis. American Naturalist 147:445-465.

Emery, R. J. N., D. M. Reid, and C. C. Chinnappa. 1994. Phenotypic plasticity of stem elongation in two ecotypes of Stellaria longipes: the role of ethylene and response to wind. Plant, Cell and Environment 17:691-700.

Farris, M. A., and M. J. Lechowicz. 1990. Functional interactions among traits that determine reproductive success in a native annual plant. Ecology 71:548-557.

Fitter, A. H., and C. J. Ashmore. 1974. Response of Veronica species to a simulated woodland light climate. New Phytologist 73:997-1001.

Gartner, B. L. 1991. Relative growth rates of vines vs. shrubs of poison oak, Toxicodendron diversilobum (Anacardiaceae). American Journal of Botany 78: 1345-1353.

Gedroc, J. J., K. D. M. McConnaughay, and J. S. Coleman. 1996. Plasticity in root/shoot partitioning: optimal, ontogenetic, or both? Functional Ecology 10:44-50.

Gleeson, S. K., and D. Tilman. 1992. Plant allocation and the multiple limitation hypothesis. American Naturalist 139:1322-1343.

Horrell, B. A., P. E. Jameson, and P. Bannister. 1990. Responses of ivy (Hedera helix) to combinations of gibberellic acid, paclobutrazol, and abscisic acid. Plant Growth Regulation 9:107-117.

Jaffe, M. J., and S. Forbes. 1993. Thigmomorphogenesis: the effect of mechanical perturbation on plants. Plant Growth Regulation 12:313-324.

Lefevre, J. C., J. Bigot, and J. Bouchaud. 1991. Origin of foliar nitrogen and changes in free amino-acid composition and content in leaves, stubble, and roots of perennial ryegrass during regrowth after defoliation. Journal of Experimental Botany 42:89-95.

Lentz, K. A., and D. F. Cipollini. 1998. The effect of light and simulated herbivory on growth of endangered northeastern bulrush Scirpus ancistrochaetus Schuyler. Plant Ecology 139:125-131.

Lester, D. R., J. J. Ross, P. J. Davies, and J. B. Reid. 1997. Mendel's stem length gene (Le) encodes a gibberellin $3 \beta$-hydroxylase. Plant Cell 9:1435-1443.

Lopez-Juez, E., M. Kobayashi, A. Sakurai, Y. Kamiya, and R. E. Kendrick. 1995. Phytochrome, gibberellins, and hypocotyl growth: a study using the cucumber (Cucumis sativus L.) long hypocotyl mutant. Plant Phvisology 107: 131-140.

MacDonald, S. E., D. M. Reid, and C. C. Chinnappa. 1986. Studies on the Stellaria longipes complex: phenotypic plasticity. II. Gibberellins, abscisic acid, and stem elongation. Canadian Journal of Botany 64:2617-2621.

Methy, M., and J. Roy. 1993. Morphogenetic changes induced by a low red : far-red ratio and their growth con- sequences in water hyacinth (Eichornia crassipes). Lournal of Experimental Botany 44:1275-1280.

Mihaliak, C. A., and D. E. Lincoln. 1989. Plant biomass partitioning and chemical defense: response to defoliation and nitrate limitation. Oecologia (Berlin) 80: 122-126.

Morris, D. A., and E. D. Arthur. 1985. Effects of gibberellic acid on patterns of carbohydrate distribution and acid invertase activity in Phaseolus vulgaris. Phvsiologia Plantarum 65:257-262.

Mulligan, D. R., and J. W. Patrick. 1979. Gibberellic-acidpromoted transport of assimilates in stems of Phaseolus vulgaris L.: localized versus remote site(s) of action. Planta 145:233-238.

Niklas, K. J. 1992. Plant biomechanics—an engineering approach to plant form and function. University of Chicago Press, Chicago.

Obeso, J. R., and P. J. Grubb. 1994. Interactive effects of extent and timing of defoliation and nutrient supply on reproduction in a chemically protected annual Senecio vulgaris. Oikos 71:506-514.

Ovaska, J., M. Walls, and E. Vapaavuori. 1993. Combined effects of partial defoliation and nutrient availability on cloned Betula pendula saplings. Lournal of Experimental Botany 44:1385-1393.

Perrin, N. 1992. Optimal resource allocation and the marginal value of organs. American Naturalist 139: 1344-1369.

Petit, C., and J. D. Thompson. 1997. Variation in phenotypic response to light availability between diploid and tetraploid populations of the perennial grass $A r$ rhenatherum elatius from open and woodland sites. Iournal of Ecology 85:657-667.

Pigliucci, M. 1996. How organisms respond to environmental changes: from phenotypes to molecules (and vice versa). Trends in Ecologv \& Evolution 11:168-173.

- 1997. Ontogenetic phenotypic plasticity during the reproductive phase in Arabidopsis thaliana (Brassicaceae). American Journal of Botany 84:887-895.

Rajapakse, N. C., and J. W. Kelly. 1995. Regulation of Chrysanthemum growth by spectral filters. Journal of the American Society of Horticultural Science 117: 481-485.

Rood, S. B., P. H. Williams, D. Pearce, N. Murofushi, L. N. Mander, and R. P. Pharis. 1990. A mutant gene that increases gibberellin production level in Brassica. Plant Physiology 93:1168-1174.

Rosenthal, J. P., and P. M. Kotanen. 1994. Terrestrial plant tolerance to herbivory. Trends in Ecology \& Evolution 14:145-148.

Salisbury, F. B., and C. W. Ross. 1992. Plant physiology. Wadsworth, Belmont, Calif. 
SAS Institute. 1989. SAS/STAT user's guide, version 6. Vol. 2. SAS Institute, Cary, N.C.

Schmitt, J., A. C. McCormac, and H. Smith. 1995. A test of the adaptive plasticity hypothesis using transgenic and mutant plants disabled in phytochrome-mediated elongation responses to neighbors. American Naturalist 146:937-953.

Sinervo, B., and R. B. Huey. 1990. Allometric engineering: an experimental test of the causes of interpopulational differences in performance. Science (Washington, D.C.) 248:1106-1109.

Smith, H. 1982. Light quality, photoperception, and plant strategy. Annual Review of Plant Physiology 33:481-518.

Smith, H., and G. C. Whitelam. 1990. Phytochrome, a family of photoreceptors with multiple physiological roles. Plant, Cell and Environment 13:695-707.

Sponsel, V. M. 1986. Gibberellins in dark- and red-lightgrown shoots of dwarf and tall cultivars of Pisum sativum: the quantification, metabolism, and biological activity of gibberellins in Progress No. 9 and Alaska. Planta 168:119-129.

Stearns, S. C. 1992. The evolution of life histories. Oxford University Press, Oxford.

Sultan, S. E. 1995. Phenotypic plasticity and plant adaptation. Acta Botanica Neerlandica 44:363-383.

Tilman, D. 1988. Plant strategies and the dynamics and structure of plant communities. Princeton University Press, Princeton, N.J.

Toyomasu, T., H. Yamane, N. Morofushi, and P. Nick. 1994. Phytochrome inhibits the effectiveness of gibber- ellins to induce cell elongation in rice. Planta 194: 256-263.

Trewavas, A. 1986. Resource allocation under poor growth conditions: a major role for growth substances in developmental plasticity. Pages 31-76 in D. Jennings and A. Trewavas, eds. Plasticity in plants. Symposia of the society for experimental biology, no. 30. Company of Biologists, Cambridge.

van der Meijden, E., M. Wijn, and H. J. Verkaar. 1988. Defence and regrowth, alternative plant strategies in the struggle against herbivores. Oikos 51:355-363.

van Hinsberg, A. 1997. Morphological variation in Plantago lanceolata: effects of light quality and growth regulators on sun and shade populations. Journal of Evolutionary Biology 10:687-702.

Wang, J., N. E. Ives, and M. J. Lechowicz. 1992. The relation of foliar phenology to xylem embolism in trees. Functional Ecology 6:469-475.

Weiner, J., and S. C. Thomas. 1992. Competition and allometry in three species of annual plants. Ecology 73: 648-656.

Yim, K.-O., Y. W. Kwon, and D. E. Bayer. 1997. Growth responses and allocation of assimilates of rice seedlings by paclobutrazol and gibberellin treatment. Journal of Plant Growth Regulation 16:35-41.

Zera, A. J., J. Potts, and K. Kobus. 1998. The physiology of life-history trade-offs: experimental analysis of a hormonally induced life-history trade-off in Gryllus assimilis. American Naturalist 152:7-23.

Associate Editor: Mark A. McPeek 